\title{
Cardiac Arrest Cases and Automated External Defibrillator Use in Railroad Stations in Tokyo
}

\author{
Satoko Fukuike, Yasuhiro Otomo \\ Department of Acute Critical Care and Disaster Medicine, Tokyo Medical and Dental University, Tokyo, Japan \\ Email: otomo.accm@tmd.ac.jp
}

Received 18 September 2014; revised 25 October 2014; accepted 13 November 2014

Copyright (C) 2014 by authors and Scientific Research Publishing Inc.

This work is licensed under the Creative Commons Attribution International License (CC BY). http://creativecommons.org/licenses/by/4.0/

c) (i) Open Access

\section{Abstract}

Objective: Nationwide dissemination of public-access defibrillation (PAD) contributed to an increase of survival rate in Japan. We analysed cardiac arrests (CAs) that occurred in railroad stations in Tokyo to evaluate PAD in the metropolis. Methods: We collected Utstein data from the Tokyo Fire Department (TFD) and analysed CA cases that occurred in stations. In total, 245 non-traumatic CAs from January 1, 2007 to March 31, 2008 were analysed; CAs in children under 8 years were excluded. Results: The rates of pre-hospital return of spontaneous circulation (ROSC) were 41 out of 145 witnessed CA patients (28.3\%) and 12 ROSC out of 100 unwitnessed CA patients (12\%). Of 245 CA cases, bystander cardiopulmonary resuscitation (CPR) performed in $156(63.7 \%)$, automated external defibrillator (AED) used in $117(47.8 \%)$ and shock delivered in $65(26.5 \%)$. Rates of ROSC were $31.6 \%(37 / 117)$ with AED use significantly higher than those of $12.5 \%(16 / 128)$ without AED use $(P<0.001)$. Most CAs occurred on platforms; the use of AEDs on platforms increased from $18 / 31$ (58.1\%) in 2007 to $32 / 43(74.4 \%)$ in 2008 and ROSC rates increased from $8(25.8 \%)$ to $14(32.6 \%)$, respectively. On train CAs: ROSC cases were very few, 1 case each year $(8.3 \%$; $7.7 \%)$ while the use of AED increased from 8/12 (66.7\%) in 2007 to 10/13 (76.9\%) in 2008. Conclusion: Bystander CPR and the use of AED at railroad stations improved ROSC for out-of-hospital cardiac arrest (OHCA) patients. AED location and strategies for dealing with CAs on trains should be re-evaluated.

\section{Keywords}

Automated External Defibrillator, Public Access Defibrillation, Station

\section{Introduction}

The Japanese Ministry of Health, Labour and Welfare approved public access defibrillation (PAD) in 2004 [1].

How to cite this paper: Fukuike, S. and Otomo, Y. (2014) Cardiac Arrest Cases and Automated External Defibrillator Use in Railroad Stations in Tokyo. International Journal of Clinical Medicine, 5, 1328-1336. 
This has led to an increase in the availability of automated external defibrillators (AEDs) in public places. AED in schools reached to almost 100\% [2]. 211,089 AEDs in public place such as sports facilities, community centers and stores are registered [3]. The basic life support training (BLS) including the use of AED is taught to students in elementary schools [4]. These efforts on PAD have improved the outcomes of out-of-hospital cardiac arrests (OHCA) for patients in Japan [5]. The rail network is the most important means of transportation for people living in Tokyo the capital of Japan, and the surrounding districts. In the fiscal year of 2006 (from April 1, 2006 to March 31, 2007), 8.9 out of the 12.6 billion (70.6\%) passengers in Tokyo were transported by a well-developed railroad network including subways, while 2.7 billion (21.5\%) people used cars, 969 million (7.7\%) were transported by bus and 34 million (0.3\%) were transported by aircraft and ships, respectively [6] [7]. In addition, the rail network is of particular interest as it is the site of a large number of cardiac arrest (CA) cases each year [8]-[13]. In the area under the supervision of the Tokyo Fire Department (TFD), for the 23 special administrative districts and 28 out of 30 municipalities in the Tama area [14], the data show a large number of CAs occurring in railroad facilities (hereinafter, stations); these numbers amounted to 385 in 2007 through 2008 [8] [9]. This makes railroads the fifth most common place for OHCAs and the second most common place for CAs occurring outside houses each year. The availability of AEDs in Tokyo railroad stations has been improved by the voluntary efforts of railroad companies as well as donations from local government units since September 2005 [15] [16]. However, detailed investigation into the incidence of CAs and the use of AEDs in stations was quite few [10]-[12]. We aim to analyse the use of AEDs in stations and the outcomes of CA patients and to evaluate the effectiveness of PAD.

\section{Methods}

This was a retrospective and observational study using data from the Utstein database provided by the TFD. Individuals were classified as CA if a casualty's condition was one of the following: CA confirmed when an ambulance technician contacted; not confirmed as CA when the ambulance technician contacted but became CA afterward; or spontaneous contraction (ROSC) was observed after bystander CPR when the ambulance technician contacted. Analysis of the data to determine the incidence of CAs and AED use by bystanders in stations was approved by the Emergency Medical Service Division of the TFD. CA cases in stations in Tokyo during 2 years from April 1, 2007 to December 31, 2008 were extracted from the Utstein database and analysed for the following characteristics: the address the ambulance was dispatched to, the place of incidence within the station, the month and hour of incidence, the age and gender of the patient, the type of incidence (trauma or non-trauma), the presence of witness, whether bystander-initiated cardiopulmonary resuscitation (CPR) was performed, the availability of an AED and whether it was used by bystanders, bystander defibrillation was performed or not, and whether ROSC was observed by the ambulance technician before arrival at hospital (hereinafter, ROSC). Dates and exact station names were not included in the data due to privacy protection. The name of each station where a CA case occurred was searched against the address where the ambulance was dispatched. We surveyed the availability of AEDs in stations where CA occurred by referring to the websites of the 16 railroad companies. When the information was not found in the websites, we contacted the companies by phone or e-mail to make sure the AED was available when the CA occurred in the station. Patients who had experienced trauma and children under 8 years old were excluded from the analysis. We used pre-hospital ROSC as the primary positive outcome for patients. For the statistical analysis, the $\mathrm{X}^{2}$ test was used using $\mathrm{R} 2.12 .0$, and $\mathrm{P}$ values of less than 0.05 were considered statistically significant.

\section{Results}

\subsection{Incidence}

\subsubsection{Comparison by Age and Sex}

The total number of CA cases reported at railroad stations in Tokyo was 385 from January 1, 2007 to December 31, 2008. From these, non-traumatic 245 CAs were included in our analysis. Among 245 CA cases, 207 were males (84.5\%) and 38 were females (15.5\%) (Figure 1). The majority of the CA cases were patients in their 50s or 60s, accounting for 136 (55.5\%) (Figure 1).

\subsubsection{Month and Hour of Incidence}

Fewer CA cases were reported in July, August and September than in other months; the number of cases reported in these three months was 33 (13.5\% of all cases). By comparison, the quarterly average number of cases 


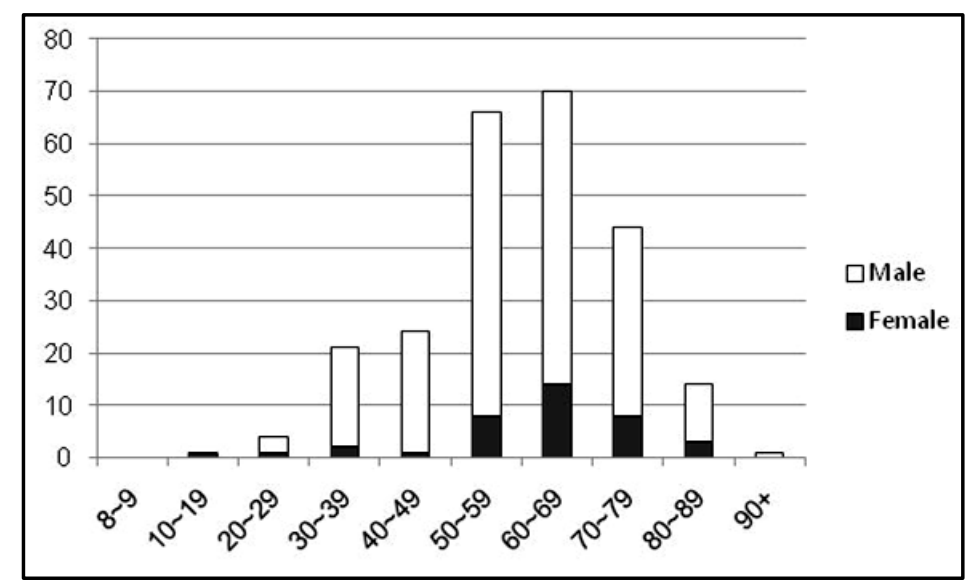

Figure 1. Incidence of CAs by age group $(n=245)$.

reported for the remainder of the year was 70.7 (28.9\%) (Figure 2(a)). With regard to the hour of incidence, at least 1 occurrence of CA was observed, except between $2 \mathrm{am}$ and $4 \mathrm{am}$. The first peak period was between 6:00 and 9:00, and subsequent peak was observed between 15:00 and 16:00 (Figure 2(b)).

\subsection{Status of Stations Where CA Cases Occurred}

\subsubsection{Total Number of Stations Where CA Cases Occurred}

Among the 765 stations operated by the 16 railroad companies under the supervision of the TFD, CAs occurred in 130 of 765 stations (17\%). Among these 130 stations, 85 (65.4\%) reported 1 case, 27 (20.8\%) reported 2 cases, 3 (2.3\%) reported 10 cases. Among 8 stations (6.2\%) reported 4 and more cases, 3 reported more than 10 cases and at most 23 cases occurred in 1 station.

\subsubsection{Availability of AEDs in Stations Where CA Cases Occurred}

There was an increase in the number of stations that were equipped with AEDs and had CAs from 80 out of 109 CA cases (73.4\%) in 2007 to 123 out of 136 CA cases (90.4\%) in 2008 (Table 1).

\subsubsection{Presence of Witness, the Number and Percentage of Cases with CPR, AED Use and Pre-Hospital ROSC}

Figure 3 shows presence of witness, rate of bystander CPR, AED use, shock delivery and ROSC. Among the 245 CA cases, 145 were witnessed (59.2\%). Among the witnessed CAs, bystander CPR was performed in 100 cases (69\%), AED use by bystander in 66 (45.5\%) and shock was delivered in 38 cases (26.2\%). ROSC was achieved in 22 shocked cases (15.2\%). Among 28 non-shockable rhythm cases, 4 attained ROSC. Among 34 cases that AED was not used, ROSC was attained in 10 cases. 36 out of 100 cases achieved ROSC (36\%) with bystander CPR, 5 out of 45 cases without bystander CPR attained ROSC (11.1\%; $P<0.05$ ) (Figure 3(a)). Among 100 unwitnessed CAs, bystander CPR was performed in 56 cases (56\%). Among 56 bystander CPR, 11 shocked cases and 1 without AED case achieved ROSC (21.4\%). There were no survivors among 44 cases without CPR group $(P<0.01)$ (Figure $3(b))$.

\subsubsection{Number and Percentage of Cases with AED Use by Bystanders in Stations with AEDs}

The number of CA cases in which AEDs were used by bystanders in suitably equipped stations increased from 41 cases out of 80 (51.3\%) in 2007 to 76 cases out of $123(61.8 \%)$ in 2008 (Table 1). In 2007, the rate of ROSCs achieved with AED use was 13 cases out of 41 (31.7\%), compared with 8 cases out of 68 (11.8\%) without AED use $(P<0.05)$, which included cases where AEDs were available but not used and where no AED was available. In 2008, the rate of ROSC was 24 cases out of 76 (31.6\%) with AED use and 8 out of 60 (13.3\%) without AED use, respectively $(P<0.05)$. ROSC achieved in 37 out of 117 CAs $(31.6 \%)$ in stations with AED and 16 out of 128 cases $(12.5 \%)$ without AED, respectively $(P<0.001)$ (Table 2). The rate of ROSC was 2 times higher with AED use than without AED. 


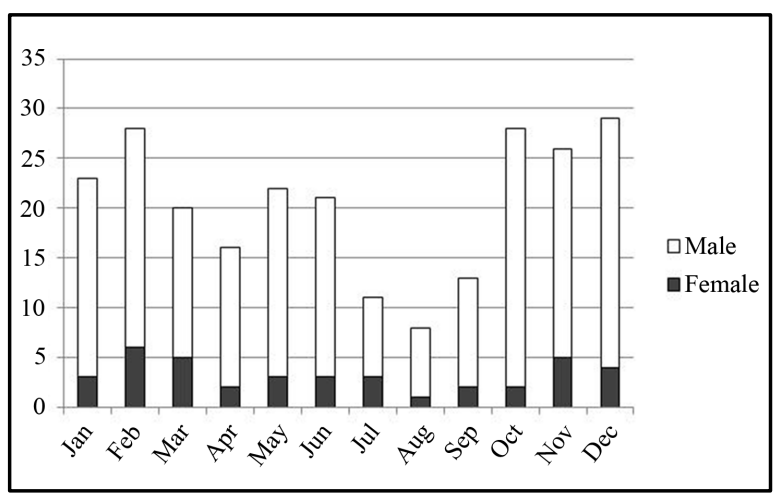

(a)



(b)

Figure 2. (a) Incidence of CAs by month; (b) Incidence of CAs by hour $(n=245)$.

Table 1. Availability of AEDs, number (percentage) of cases with AED use and number (percentage) of cases with pre-hospital ROSC.

\begin{tabular}{ccccc}
\hline Year & CA cases & Cases with AED & Cases with AED use & Cases with ROSC $^{\ddagger}$ \\
\hline 2007 & 109 & $80(73.4 \%)$ & $41(51.3 \%)$ & $21(19.3 \%)$ \\
2008 & 136 & $123(90.4 \%)$ & $76(61.8 \%)$ & $32(23.5 \%)$ \\
\hline
\end{tabular}

${ }^{*}$ Number (\%) of CA cases that occurred in stations where AEDs were available; ${ }^{\dagger}$ Number (\%) of CA cases that AED were used in stations; ${ }^{\ddagger}$ Number (\%) of cases that pre-hospital ROSC were observed.

Table 2. Number (percentage) of cases with ROSC with or without AED use.

\begin{tabular}{lcc}
\hline \multicolumn{2}{l}{ AED used } & \\
\hline & In stations with AEDs & $37 / 117(31.6 \%)^{*}$ \\
\hline \multirow{2}{*}{ AED not used } & & $16 / 128(12.5 \%)^{*}$ \\
\hline & In stations with AEDs & $9 / 86$ \\
& In stations without AEDs & $7 / 42$ \\
\hline
\end{tabular}

${ }^{*} P<0.001$.

\subsubsection{Rates of Pre-Hospital ROSC in Stations with AEDs by Site of CA Incidence}

Table 3 shows the rate of pre-hospital ROSC by site. The incidence of CAs at 7 different sites within AED equipped stations (platforms, on trains, paths, stairs, station houses, restrooms and other sites) showed a similar pattern during both years. CAs occurred most frequently on platforms, followed by paths and trains. The rates of bystander CPR and AED use in these sites each year were as follows: 19 bystander CPR; 18 AED in 31 CAs (61.3\%; 58.1\%) in 2007 and 37; 32 in 43 (86\%; 74.4\%) in 2008 on platforms; 8; 8 in 12 (66.7\%; $66.7 \%)$ in 2007 and 10; 10 in 13 (76.9\%; 76.9\%) in 2008 on trains, and 8; 8 in 15 (53.3\%; 53.3\%) in 2007 and 19 ; 15 in 26 (73\%; $57.6 \%$ ) in 2008 in paths, respectively. More cases occurred in station houses in 2008 (15 cases) than in 2007 (3 cases) (Table 3(a), Table 3(b)). The rate of ROSC increased from 8 in 31 cases (25.8\%) in 2007 to 14 in 43 cases (32.6\%) in 2008 on platforms and from 4 in 15 cases (26.7\%) in 2007 to 10 in 26 cases (36.0\%) in 2008 in paths. The rate of ROSC was extremely low on trains compared with other sites and showed no improvement over the 2 years ( 1 in 12 cases [8.3\%] in 2007; 1 in 13 cases [7.7\%] in 2008).

\section{Discussion}

Railroad stations are a major public place in which CAs occur in Japan while 9 CAs occurred in airports during the same time periods [8] [9], and ferry terminals, airports were reported as major places in other countries [17][19]. Sasaki reports that railroad stations are the most common place CAs occurred in Osaka, the second largest 




(a)

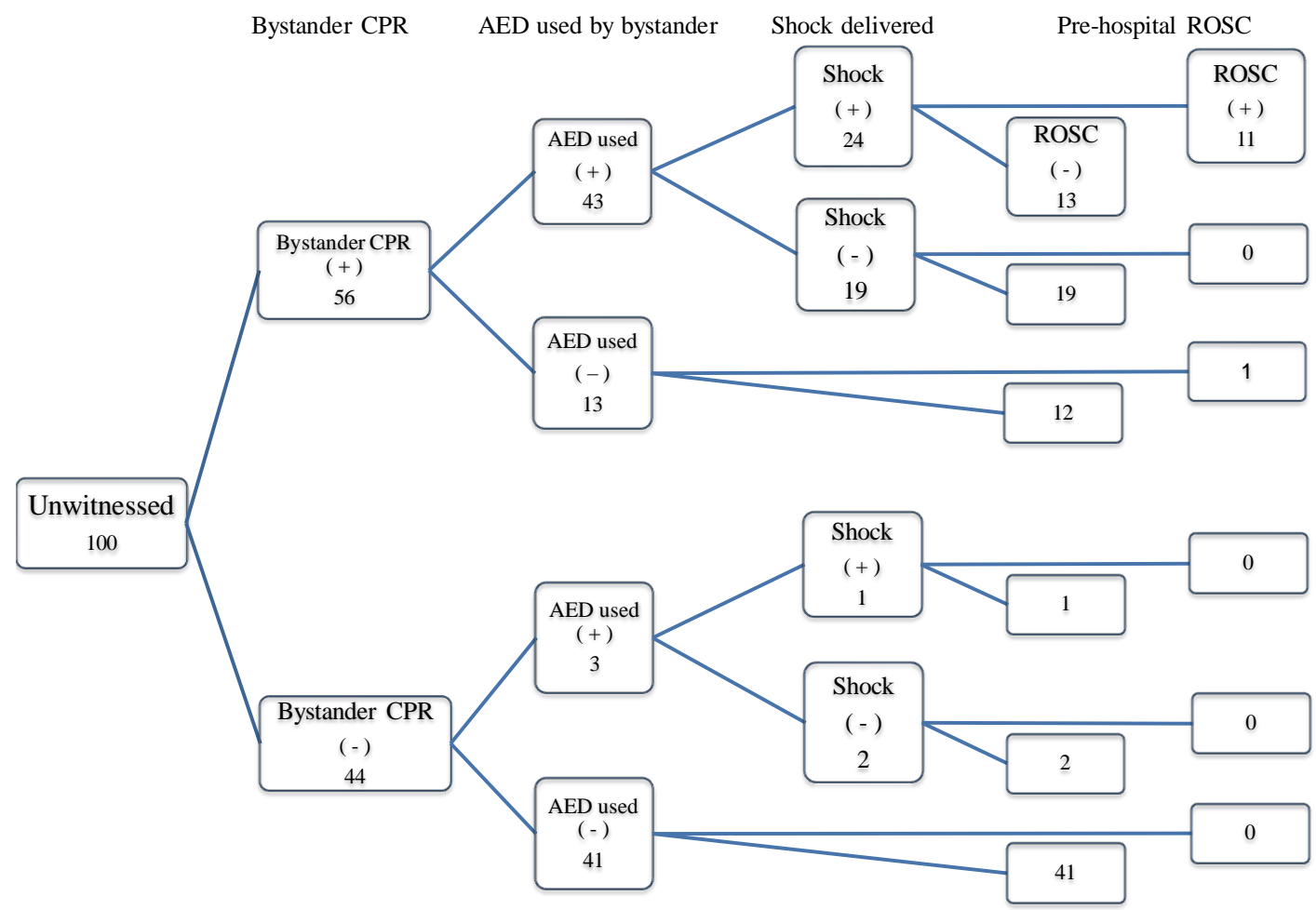

(b)

Figure 3. (a) Rates of witnessed CAs, bystander CPR, AED use by bystander, Shock delivery and pre-hospital ROSC $n=145$; (b) Rates of unwitnessed CAs, bystander CPR, AED use by bystander, Shock delivery and prehospital ROSC $n=100$. 
Table 3. (a) Rates of pre-hospital ROSC in stations with AEDs by site of CA occurrence (2007) $n=80$; (b) Rates of pre-hospital ROSC in stations with AEDs by site of CA occurrence (2008) $n=123$.

(a)

\begin{tabular}{ccccc}
\hline Site of CA Incidence & Total No. of CA Cases & Bystander CPR Number (\%) & AED Use Number (\%) & Pre-Hospital ROSC Number (\%) \\
\hline Platforms & 31 & $19(61.3)$ & $18(58.1)$ & $8(25.8)$ \\
On trains & 12 & $8(66.7)$ & $8(66.7)$ & $1(8.3)$ \\
Paths & 15 & $12(80.0)$ & $8(53.3)$ & $4(26.7)$ \\
Stairs & 3 & $1(33.3)$ & $0(0)$ & $0(0)$ \\
Station houses & 3 & $2(66.7)$ & $1(33.3)$ & $2(0)$ \\
Restroom & 4 & $3(75.0)$ & $2(50.0)$ & $1(8.3)$ \\
Other & 12 & $5(41.7)$ & $4(33.3)$ & \\
\hline
\end{tabular}

(b)

\begin{tabular}{ccccc}
\hline Site of CA Incidence & Total No. of CA Cases & Bystander CPR Number (\%) & AED Use Number (\%) & Pre-Hospital ROSC Number (\%) \\
\hline Platforms & 43 & $3(88.4)$ & $32(74.4)$ & $14(32.6)$ \\
On trains & 13 & $10(76.9)$ & $10(76.9)$ & $1(7.7)$ \\
Paths & 26 & $19(73.0)$ & $15(57.6)$ & $10(38.5)$ \\
Stairs & 3 & $1(33.3)$ & $0(0)$ & $1(33.3)$ \\
Station houses & 15 & $8(53.3)$ & $9(60.0)$ & $2(13.3)$ \\
Restroom & 7 & $2(28.5)$ & $3(42.8)$ & $0(0)$ \\
Other & 16 & $5(31.2)$ & $7(43.7)$ & $2(12.5)$ \\
\hline
\end{tabular}

city in Japan, 18 out of 48 (38\%) ventricular fibrillation (VF) patients were delivered shock during 4.5 years from July 2004 [12]. In our analysis, out of 245 non-traumatic CA patients, AED were used in 118 and shock was delivered in 65 cases in railroad stations during 2 years from January 2007 through December 2008. Of a total of 12,021 cases, CA occurred 1.47 times likely to be men than women in Tokyo [9]. There were overwhelmingly more male patients than female patients in stations. The incidence among males was 5.45 times greater than females in our analysis. According to the TFD, the majority of OHCA occurred in 50s to 60s males in public places [8] [9]. Other reports showed OHCA occurred likely 2.5 times to men than women [20]-[22]. Morita reports among 1,068 witnessed OHCA from May 1998 through April 2004 in Takatsuki city a neighbouring city of Osaka, occurrence of VF was found in men more than women in all generations, and its ratio was greatest in 50s (men 193; women 27) and followed by 60s (224; 51, respectively) [23]. Murakami reports characteristics of witnessed OHCA at public places according to the location in Osaka during 7 years from January 2005. Railroad station was the major place among public places (118/894; 13\%). Among 118 CAs in railroad stations, CA occurred in men (93; 78.8\%) more than women and 57 (48.3\%) found above 65 years [13]. To regard with the number of railroad passenger, a metropolis transportation census conducted every 5 years, 7,895,066 passengers a day used railroads with commuter pass (one way) in Tokyo and surrounding area in 2010 and the pass users occupied $63 \%$ of all passengers. In about 7.9 million pass users including $2 \%$ of unknown passengers, the number of male passenger was more than female passenger in all generations. Ratio of men to women was about 1 in younger generation under 30 years, increased to 3 in 50 to 69 years [24]. Of 7.9 million passengers, the majority was in 20 to 29 years (about 2 million) followed by 1.8 million in 30 s; 1.4 million in 40s; 0.9 million in 50s and 0.5 million in 60s [24]. In our analysis, the incidence in 20s was less than 5 cases during 2 years. In contrast, nearly 70 CA cases each occurred in 50s and 60s who those belong to minor group. These data reflect CA in railroad stations occurred more in men (Figure 1) and CA is more likely to occur in 50s to 60s. The incidence of CA was relatively low in summer and high during non-summer months. This trend is similar to overall OHCAs in Tokyo and other areas [8] [9]. In terms of hours, peak CA incidences were observed 
during peak travel hours. Morita reports that there were 2 peaks in which witnessed CA cases occurred in Japan; the first occurred at around 9 am and the second occurred at around 7 pm [23]. The metropolis transportation census shows peak hour of railroads is 7 to 8 am [24]. In our data, there was a peak in the same time periods in the morning but there was no significant difference between other peak hour around noon and $8 \mathrm{pm}$. Besides seasons and peak travel hours, relation between other environmental factors such as temperature and humidity are not certain. The rate of bystander CPR in stations was 62.4\% (68 in 109 cases) in 2007 and 64.7\% (88 in 136 cases) in 2008; both of these rates were higher than the nationwide averages (39.2\% in 2007 and $40.7 \%$ in 2008) [25]. ROSC was achieved in 21 of the 68 cases (30.9\%) in which bystander CPR was performed in 2007. In contrast, ROSC was not reported in any of the 41 cases in which CPR was not performed. In 2008, ROSC was also reported in 27 of the 88 cases (30.7\%) with bystander CPR and 5 of the 48 cases (10.4\%) without bystander $\mathrm{CPR}$, with a significantly higher rate of ROSC among the cases with bystander CPR $(P<0.01)$. A comparison of the ROSC rate between AED use and no AED use revealed a significantly higher rate of ROSC with AED use (21 in 68 cases [30.9\%] in 2007, 27 in 88 cases [30.7\%] in 2008, $P<0.001)$ than without AED ( 0 in 41 cases [0\%]; 5 in 48 cases [10.4\%], $P<0.01$ ). The rate of AED use in stations with AEDs improved from $50 \%$ in 2007 to $60 \%$ in 2008 , which could be increased even more as the presence of bystanders is expected to be high in operating stations. A comparison of ROSC rate by site revealed an improvement in the rate of AED use and a subsequent improvement in the rate of ROSC in platforms, paths and station houses. In contrast, CA cases reported on trains had a low rate of ROSC despite a high rate of bystander CPR and AED use. This may be due to various difficulties: delays in starting CPR; performing CPR in an overcrowded train car and on platform, long intervals between stops on long-distance or express lines, and delays in setting up AEDs. These impediments can be overcome by installing AEDs in platforms and train cars, educating train crews and station staff members and encouraging passengers to begin compression only resuscitation [5] [26]-[30].

\section{Limitations}

We could not gather enough data to analyse one-month survival because in case with unknown outcomes were classified as deaths (1.4\% of overall OHCAs in 2007; $2.7 \%$ in 2008). We suggest to the TFD that uncertain one-month survivals should be clearly mentioned. Data collection remained an issue in this retrospective study, with limited data collected due to the privacy policy and limited medical control system. Although the time of emergency call and an ambulance crew's arrival at the site were recorded, the time of shock was not obtained by the TFD because analysis of data in AED is upon AED owners. It is beneficial to record the time of first shock delivery for evaluation and improvement of PAD. Detailed locations of CA occurrence more than described could not be obtained. If an exact location was provided for each case, the distance and time to AED delivery could be estimated and appropriate locations could be discussed further.

\section{Conclusion}

Bystander CPR and use of AED at railroad stations improved ROSC for OHCA patients. AED location and strategies for dealing with CA on trains should be re-evaluated.

\section{Conflicts of Interest}

None.

\section{Acknowledgements}

We greatly appreciate the Emergency Medical Service Division of the Tokyo Fire Department for providing their indispensable data. We are also grateful to the personnel of the railroad companies who gave us swift replies to our enquiries.

\section{References}

[1] Health Policy Bureau, Ministry of Health, Labour and Welfare (2014). (In Japanese) http://plaza.umin.ac.jp/GHDNet/04/AED_iseirei7010011.pdf

[2] Ministry of Education, Culture, Sports, Science and Technology (2014) Survey on AED Deployment in Schools. (In 
Japanese)

http://www.mext.go.jp/component/a_menu/education/detail/__icsFiles/afieldfile/2012/04/04/1289307_04.pdf

[3] Japan Foundation for Emergency Medicine (2014) AED Map. (In Japanese) http://www.qqzaidan.jp/AED/aed.htm

[4] (In Japanese) http://www.mext.go.jp/a_menu/kenko/anzen/_icsFiles/afieldfile/2014/09/09/1351843_01.pdf

[5] Kitamura, T., Iwami, T., Kawamura, T., Nagano, K., Tanaka, H., et al. (2010) Nationwide Public-Access Defibrillation in Japan. The New England Journal of Medicine, 362, 994-1004. http://dx.doi.org/10.1056/NEJMoa0906644

[6] Japan Transport Promotion Association (2009) Suji de miru Kanto no un-yu no ugoki (Statistic of Transport in Kanto Area, Japan). Japan Transport Promotion Association. (In Japanese)

[7] Ministry of Land, Infrastructure, Transport and Tourism (2014) White Paper on Land, Infrastructure, Transport and Tourism in Japan, 2008. http://www.mlit.go.jp/common/000221175.pdf

[8] Tokyo Fire Department (2007) Kyukyukatsudo no genkyo (Statistic, Emergency Medical Services on Tokyo Fire Department). (In Japanese)

[9] Tokyo Fire Department (2008) Kyukyukatsudo no genkyo (Statistic, Emergency Medical Services on Tokyo Fire Department). (In Japanese)

[10] Muraoka, H., Ohishi, Y., Hazui, H., Negoro, N., Murai, M., Kwakami, M., et al. (2006) Location of Out-of-Hospital Cardiac Arrests in Takatsuki City- Where Should Automated External Defibrillator Be Placed? Circulation Journal, 70, 827-831. http://dx.doi.org/10.1253/circj.70.827

[11] Iwami, T., Hiraide, A., Nakanishi, N., Hayashi, Y., Nishiuchi, T., Yukioka, H., et al. (2003) Age and Sex Analyses of Out-of-Hospital Cardiac Arrest in Osaka, Japan. Resuscitation, 57, 145-152. http://dx.doi.org/10.1016/S0300-9572(03)00035-2

[12] Sasaki, M., Iwami, T., Kitamura, T., Nomoto, S., Nishiyama, C., Sakai, T., et al. (2011) Incidence and Outcome of Outof-Hospital Cardiac Arrest with Public-Access Defibrillation-A Descriptive Epidemiological Study in a Large Urban Community. Circulation Journal, 75, 2821-2826. http://dx.doi.org/10.1253/circj.CJ-11-0316

[13] Murakami, Y., Iwami, T., Kitamura, T., Nishiyama, C., Nishiuchi, T., Hayashi, Y. et al. (2014) Outcomes of Out-ofHospital Cardiac Arrest by Public Location in the Public-Access Defibrillation Era. Journal of the American Heart Association, 3, 1-11. http://jaha.ahajournals.org/content/3/2/e000533.full

[14] http://www.metro.tokyo.jp/ENGLISH/PROFILE/overview02.htm

[15] (In Japanese) http://www.jreast.co.jp/press/2005_1/20050607.pdf

[16] (In Japanese) http://www.tokyometro.jp/news/2005/2005-26.html

[17] Ong, M.E.H., Tan, E.H., Yan, X., Anushia, P., Lim, S.H., Leong, B.S.H., et al. (2008) An Observational Study Describing the Geographic-Time Distribution of Cardiac Arrests in Singapore: What Is the Utility of Geographic Information Systems for Planning Public Access Defibrillation? (PADS Phase I). Resuscitation, 76, 388-396. http://dx.doi.org/10.1016/j.resuscitation.2007.09.006

[18] MacDonald, R., Mottley, J. and Weinstein, C. (2002) Impact of Prompt Defibrillation on Cardiac Arrest at a Major International Airport. Prehospital Emergency Care, 6, 1-5. http://dx.doi.org/10.1080/10903120290938689

[19] Engdahl, J. and Herlitz, J. (2005) Localization of Out-of-Hospital Cardiac Arrest in Goteborg 1994-2002 and Implications for Public Access Defibrillation. Resuscitation, 64, 171-175. http://dx.doi.org/10.1016/j.resuscitation.2004.08.006

[20] Kim, C., Fahrenbruch, C.E., Cobb, L.A. and Eisenberg, M.S. (2001) Out-of-Hospital Cardiac Arrest in Men and Women. Circulation, 104, 2699-2703. http://dx.doi.org/10.1161/hc4701.099784

[21] Rea, T.D., Olsufka, M., Bemis, B., White, L., Yin, L., Becker, L., et al. (2010) A Population-Based Investigation of Public Access Defibrillation: Role of Emergency Medical Services Care. Resuscitation, 81, 163-167. http://dx.doi.org/10.1016/j.resuscitation.2009.10.025

[22] Iwami, T., Hiraide, A., Nakanishi, N., Hayashi, Y., Nishiuchi, T., Uejima, T., et al. (2006) Outcome and Characteristics of Out-of-Hospital Cardiac Arrest According to Location of Arrest: A Report from a Large-Scale, PopulationBased Study in Osaka, Japan. Resuscitation, 69, 221-228. http://dx.doi.org/10.1016/j.resuscitation.2005.08.018

[23] Morita, H. (2006) Sudden Cardiac Death: Out-of-Hospital Care and Improving Survival. Japanese Journal of Electrocardiology, 26, 134-143. (In Japanese) http://dx.doi.org/10.5105/jse.26.134

[24] Ministry of Land, Infrastructure, Transport and Tourism (2014) Metropolis Transportation Census. (In Japanese) http://www.mlit.go.jp/sogoseisaku/transport/daitoshicensus/h22cencus-shuto.pdf

[25] Fire and Disaster Management Agency, Ministry of Internal Affairs and Communications (2014). (In Japanese) http://www.fdma.go.jp/neuter/topics/kyukyukyujo_genkyo/h25/01_kyukyu.pdf

[26] Osaka Life Support, Push Project. (In Japanese) http://osakalifesupport.jp/push/course.html 
[27] J-PULSE. (In Japanese) http://j-pulse.umin.jp/push3/index.html

[28] Iwami, T., Kawamura, T., Hiraide, A., Berg, R.A., Hayashi, Y., Nishiuchi, T., et al. (2007) Effectiveness of BystanderInitiated Cardiac-Only Resuscitation for Patients with Out-of-Hospital Cardiac Arrest. Circulation, 116, 2900-2907. http://dx.doi.org/10.1161/CIRCULATIONAHA.107.723411

[29] SOS-KANTO Study Group (2007) Cardiopulmonary Resuscitation by Bystanders with Chest Compression Only: An Observational Study. The Lancet, 369, 920-926. http://dx.doi.org/10.1016/S0140-6736(07)60451-6

[30] Ramaraj, R. and Ewy, G.A. (2009) Rationale for Continuous Chest Compression Cardiopulmonary Resuscitation. Heart, 95, 1978-1982. http://dx.doi.org/10.1136/hrt.2009.174268 
Scientific Research Publishing (SCIRP) is one of the largest Open Access journal publishers. It is currently publishing more than 200 open access, online, peer-reviewed journals covering a wide range of academic disciplines. SCIRP serves the worldwide academic communities and contributes to the progress and application of science with its publication.

Other selected journals from SCIRP are listed as below. Submit your manuscript to us via either submit@scirp.org or Online Submission Portal.

